\title{
The steady-state crystal size of deforming ice
}

\author{
T. H. JACKA \\ Antarctic Cooperative Research Centre, Box 252C, Hobart, Tasmania 7001, Australia and Australian Antarctic Division \\ LI JUN \\ Antarctic Cooperative Research Centre, Box 252C, Hobart, Tasmania 7001, Australia
}

\begin{abstract}
Previous studies have established that, together with the development of a preferred crystal-orientation fabric in ice undergoing creep deformation to high strains, there also develops a tertiary equilibrium crystal size, i.e. the crystal size, rather than affecting the creep rate, is a result of the deformation to large strains.

Equilibrium crystal size is considered here as a "balance" between crystal growth with time as a function of temperature and crystal change as a result of temperaturedependent deformation. The temperature effects in these two processes (Arrhenius relation) are similar and consideration of the activation energies for the two processes indicates that it may be appropriate to cancel them, yielding a dependence of equilibrium crystal size on stress alone. The results from laboratory experiments of steady-state crystal size plotted as a function of stress support the above proposition.

The possibility of using the relationships between steady-state crystal size and deviatoric stress as a polar ice-mass piezometer is discussed.
\end{abstract}

\section{BACKGROUND}

It is well established that for polycrystalline ice under no (or very low) stress, the crystal size increases with time at a rate dependent on the temperature (Stephenson, 1967; Gow, 1969, 1970; Budd, 1972; Gow and Williamson, 1976, for Antarctic ice; Herron, 1982, for Greenland ice; Seligman, 1949, 1950; Kamb, 1964, for laboratory observations). Results from deep ice cores collected from Byrd Station, Antarctica (Gow and Williamson, 1976), Dome C, Antarctica (Duval and Lorius, 1980\}, Vostok, Antarctica (Korotkevich and others, 1978), Law Dome, Antarctica (Young and others, 1985) and Camp Century, Greenland (Hcrron, 1982) indicate that the increase in crystal size with time and depth can be disturbed by other factors. Several explanations have been offered for these observed crystal-size variations (Paterson, 1981), and Petit and others (1987) examined the possibility of using the ice-core crystal-size variation as an indicator of past climatic temperatures. Gow and Williamson (1976) proposed that increased shear deformation could have inhibited the expected crystal growth. The results from Cape Folger, Antarctica, given by Russell-Head and Budd (1979), also show a relation between ice deformation and crystal size varying through the ice-core depth. More recently, marked crystal-size variations have been noted in the new deep ice cores, e.g. at Dye 3, Greenland (Fisher and Koerner, 1986) and at DSS on Law Dome, Antarctica (Li and Jacka, 1994). These crystal-size variations have been associated with the contemporaneous preferred crystal-orientation fabric development and with zones of high shear in the ice sheets.
For laboratory ice-deformation experiments to strains in excess of $\sim 15 \%$, it has been observed that, together with the development of a crystal-orientation fabric pattern (which depends on the stress configuration), there are also systematic changes in the mean crystal size, leading to an equilibrium crystal size at high strains (Jacka and Maccagnan, 1984). Jacka (1984) found that the change in mean crystal size could involve a decrease (if the initial crystal size was larger than the equilibrium crystal size) or an increase (if the initial crystal size was smaller than the equilibrium crystal size). Gao and Jacka (1987) further studied this equilibrium crystal-size devclopment. They found that the equilibrium crystal size seemed dependent only on the deformation-test parameters (temperature, stress, stress configuration). It was independent of (i) whether the test specimen was laboratory-prepared or cut from an ice core drilled from a natural ice mass, (ii) whether the ice was initially isotropic or initially anisotropic, although this affected the amount of strain required for the development of the equilibrium size, or (iii) the initial crystal size. Gao and Jacka concluded that, together with the attainment of a constant tertiary strain rate (for constant-stress exper-iments), the establishment of an unchanging preferred crystal-orientation fabric pattern and an unchanging equilibrium crystal size was indicative of steady-state ice flow.

It is interesting to note that similar results to those outlined above were found by Steinemann (1958). Crystal sizes in tertiary creep were determined as a function of stress and temperature by Steinemann for high stresses. In this paper, we use some already published results and some new results to examine further the 
dependence of steady-state tertiary crystal size on temperature and stress.

Some authors (see, for example, the review by Paterson (1991)) have proposed that the presence of impurities (both soluble and insoluble) may inhibit crystal growth in natural ice masses. It should be noted that this proposition is not examincd in this paper.

\section{A THEORETICAL APPROACH}

Observations from surface snow, firn and ice cores have shown that in the absence of non-hydrostatic stress, the crystal linear dimension $D$ will increase with time $t$ at a temperature $\theta$-dependent rate estimated by the relation (Stephenson, 1967; Gow, 1969, 1970):

$$
D^{2}=D_{0}^{2}+K_{0} t f(\theta)
$$

where $D_{0}$ is an initial crystal linear dimension, $K_{0}=$ $1.86 \times 10^{-2} \mathrm{~mm}^{2} \mathrm{a}^{1}$ at $\cdots 17^{\circ} \mathrm{C}$, and the form of $f(\theta)$ is discussed later. It follows immediately that the crystalgrowth ratc (the increase in average crystal area within a cross-section of a sample of polycrystalline ice) under little or no deviatoric stress can be expressed in the form:

$$
\begin{aligned}
\frac{\mathrm{d}\left(D^{2}\right)}{\mathrm{d} t}=f_{1}(\theta) \\
\Rightarrow 2 D \frac{\mathrm{d} D}{\mathrm{~d} t}=f_{1}(\theta) .
\end{aligned}
$$

For ice that is subject to a non-hydrostatic stress, the relationship between strain rate and deviatoric stress on individual crystals of polycrystalline ice has the same form as that for the bulk sample (Weertman, 1983) and can be written:

$$
\frac{1}{D} \frac{\mathrm{d} D}{\mathrm{~d} t}=f_{2}(\tau, \theta)
$$

where $\tau$ is the deviatoric stress.

The observations indicate that, in steady-state tertiary creep, the crystal size remains constant while the sample deforms. It is therefore hypothesized that the rate of change of crystal size due to strain is balanced by change due to differential crystal growth or grain-boundary migration. Therefore, equating $\mathrm{d} D / \mathrm{d} t$ from Equations (1) and (2), and designating the equilibrium linear dimension $D_{e}$,

$$
\begin{aligned}
D_{\mathrm{e}} f_{2}(\tau, \theta) & =\frac{f_{1}(\theta)}{2 D_{\mathrm{e}}} \\
\Rightarrow D_{\mathrm{e}}{ }^{2} & =\frac{f_{1}(\theta)}{2 f_{2}(\tau, \theta)}
\end{aligned}
$$

$f_{1}(\theta)$ has the form (usually referred to as the Arrhenius relation):

$$
f_{1}(\theta) \propto \exp \left(\frac{-Q^{\prime}}{R \theta}\right)
$$

where $Q^{\prime}$ is the activation energy for crystal growth and $R$ is the gas constant.
Equation (2) is an expression for the crystallographic strain rate. The temperature-dependence of this flow law also obeys the Arrhenius relation (Glen, 1955), i.e.

$$
f_{2}(\tau, \theta) \propto \exp \left(\frac{-Q^{\prime \prime}}{R \theta}\right) \tau^{n}
$$

where $Q^{\prime \prime}$ is the activation energy for ice creep and $n$ is a power-law constant, usually considered equal to 3 for ice in the stress and temperature range under consideration.

From Equation (3), then

$$
D_{\mathrm{e}}^{2} \propto \frac{1}{2} \exp \left(\frac{Q^{\prime \prime}-Q^{\prime}}{R \theta}\right) \frac{1}{\tau^{n}} .
$$

It might therefore be expected firstly that at any specified temperature,

$$
D_{\mathrm{c}}^{2} \propto 1 / \tau^{3}
$$

and secondly, that if the activation energies for the two processes are similar, the term

$$
\exp \left(\frac{Q^{\prime \prime}-Q^{\prime}}{R \theta}\right)
$$

will be near 1 and the temperature dependence on the equilibrium steady-state crystal size will be small.

Wecrtman (1973) observed that the activation energies for these two processes were similar. We now investigate this similarity in more detail with some new data, particularly at temperatures near the melting point.

\section{THE ACTIVATION ENERGIES FOR GREEP AND FOR CRYSTAL GROWTH}

Activation energies for ice creep at an octahedral stress of $0.1 \mathrm{MPa}$ have been presented by Budd and Jacka (1989) for the temperature range $-0.05^{\circ}$ to $-50^{\circ} \mathrm{C}$. Further icecreep data at the same stress have been presented since then (Morgan, 1991), from which we can estimate activation energies at temperatures higher than $-1{ }^{\circ} \mathrm{C}$.

While these data are at one stress of $0.1 \mathrm{MPa}$, Budd and Jacka (1989) showed in addition that the minimum strain rate versus temperature plots are parallel, therefore resulting in the same activation energies, over a large range of stress.

Table 1 shows the calculation of ice-creep activation energies from a set of data compiled from Budd and Jacka (1989) and Morgan (1991). The activation energy is calculated (e.g. Poirier, 1985) by

$$
Q=-k \frac{\ln \left(\dot{\epsilon}_{2} / \dot{\epsilon}_{1}\right)}{\left(1 / T_{2}-1 / T_{1}\right)}
$$

where $\dot{\epsilon}_{1}$ and $\dot{\epsilon}_{2}$ are steady-state creep (or crystal-growth) rates at two similar temperatures, $T_{1}$ and $T_{2}(\mathrm{~K})$, and $k=$ $1.38 \times 10^{-23} \mathrm{~J} \mathrm{~mole}^{-1} \mathrm{~K}^{-1}$ is Boltzmann's constant. Usually, in order to obtain the energy per mole, $k$ is replaced by $R$ (the gas constant) where $R=k N$ and $N=6.024 \times$ $10^{23}$ is Avogadro's number. Thus, $R=8.31 \mathrm{~J} \mathrm{~mole}^{-1} \mathrm{~K}^{-1}$.

These calculations have been carried out in Table 1 for minimum isotropic creep rates. Minimum creep rates 
Table 1. Calculation of activation energy for ice creep at minimum strain rate

\begin{tabular}{|c|c|c|c|c|c|c|}
\hline$\theta_{1},{ }^{\circ} \mathrm{C}$ & -0.01 & -0.03 & -0.05 & -0.10 & 0.20 & 0.50 \\
\hline$\theta_{2},{ }^{\circ} \mathrm{C}$ & -0.03 & -0.05 & -0.10 & -0.20 & -0.50 & -1.00 \\
\hline $1 / T_{1}, \mathrm{~K}^{-1}$ & $3.66 \times 10^{3}$ & $3.66 \times 10^{3}$ & $3.66 \times 10^{-3}$ & $3.66 \times 10^{-3}$ & $3.67 \times 10^{-3}$ & $3.67 \times 10^{3}$ \\
\hline $1 / T_{2}, \mathrm{~K}^{-1}$ & $3.66 \times 10^{3}$ & $3.66 \times 10^{3}$ & $3.66 \times 10^{3}$ & $3.67 \times 10^{-3}$ & $3.67 \times 10^{-3}$ & $3.68 \times 10^{3}$ \\
\hline$\left(1 / T_{2}-1 / T_{1}\right), \mathrm{K}^{-1}$ & $2.68 \times 10^{7}$ & $2.68 \times 10^{7}$ & $6.71 \times 10^{7}$ & $1.34 \times 10^{-6 \mathrm{j}}$ & $4.04 \times 10^{6}$ & $6.75 \times 10^{-6}$ \\
\hline$\dot{\epsilon}_{1}, s^{1}$ & $2.80 \times 10^{8}$ & $1.70 \times 10^{8}$ & $5.80 \times 10^{9}$ & $5.20 \times 10^{9}$ & $4.60 \times 10^{9}$ & $3.30 \times 10^{-9}$ \\
\hline$\dot{\epsilon}_{2}, s^{1}$ & $1.70 \times 10^{-8}$ & $5.80 \times 10^{-9}$ & $5.20 \times 10^{-9}$ & $4.60 \times 10^{9}$ & $3.30 \times 10^{9}$ & $3.00 \times 10^{9}$ \\
\hline $\ln \left(\dot{\epsilon}_{2} / \dot{\epsilon}_{1}\right)$ & -0.499 & 1.075 & -0.109 & -0.123 & -0.332 & -0.095 \\
\hline \multicolumn{7}{|c|}{$\ln \left(\dot{\epsilon}_{2} / \dot{\epsilon}_{1}\right) /\left(1 / T_{2}-1 / T_{1}\right)$} \\
\hline $\mathrm{K}$ & $-1.86 \times 10^{6}$ & $-4.01 \times 10^{6}$ & $-1.63 \times 10^{5}$ & $-9.13 \times 10^{4}$ & $-8.23 \times 10^{4}$ & $-1.41 \times 10^{4}$ \\
\hline$Q, \mathrm{~kJ} \mathrm{~mol}{ }^{\prime}$ & 15450 & 33291 & 1352 & 758 & 684 & 117 \\
\hline$\theta_{1},{ }^{\circ} \mathrm{C}$ & -1.00 & -5.00 & -10.00 & -20.00 & -30.00 & -40.00 \\
\hline$\theta_{2},{ }^{\circ} \mathrm{C}$ & -5.00 & -10.00 & 20.00 & 30.00 & -40.00 & -50.00 \\
\hline $1 / T_{1}, \mathrm{~K}^{-1}$ & $3.68 \times 10^{-3}$ & $3.73 \times 10^{-3}$ & $3.80 \times 10^{-3}$ & $3.95 \times 10^{3}$ & $4.12 \times 10^{-3}$ & $4.29 \times 10^{3}$ \\
\hline $1 / T_{2}, \mathrm{~K}^{-1}$ & $3.73 \times 10^{-3}$ & $3.80 \times 10^{-3}$ & $3.95 \times 10^{-3}$ & $4.12 \times 10^{-3}$ & $4.29 \times 10^{3}$ & $4.48 \times 10^{3}$ \\
\hline$\left(1 / T_{2}-1 / T_{1}\right), \mathrm{K}^{-1}$ & $5.49 \times 10^{-5}$ & $7.09 \times 10^{-5}$ & $1.50 \times 10^{-4}$ & $1.63 \times 10^{-4}$ & $1.77 \times 10^{-4}$ & $1.92 \times 10^{-4}$ \\
\hline$\dot{\epsilon}_{1}, \mathrm{~s}^{1}$ & $3.00 \times 10^{-9}$ & $9.30 \times 10^{-10}$ & $5.20 \times 10^{-10}$ & $1.30 \times 10^{-10}$ & $3.60 \times 10^{-11}$ & $8.00 \times 10^{-12}$ \\
\hline$\dot{\epsilon}_{2}, s^{1}$ & $9.30 \times 10^{10}$ & $5.20 \times 10^{-10}$ & $1.30 \times 10^{-10}$ & $3.60 \times 10^{11}$ & $8.00 \times 10^{-12}$ & $1.50 \times 10^{12}$ \\
\hline $\ln \left(\dot{\epsilon}_{2} / \dot{\epsilon}_{1}\right)$ & 1.171 & -0.581 & -1.386 & -1.284 & -1.504 & 1.674 \\
\hline \multicolumn{7}{|c|}{$\ln \left(\dot{\epsilon}_{2} / \dot{\epsilon}_{1}\right) /\left(1 / T_{2}-1 / T_{1}\right)$} \\
\hline $\mathrm{K}$ & $-2.13 \times 10^{4}$ & $-8.20 \times 10^{3}$ & $-9.22 \times 10^{3}$ & $-7.89 \times 10^{3}$ & $-8.52 \times 10^{3}$ & $-8.70 \times 10^{3}$ \\
\hline$Q, \mathrm{~kJ} \mathrm{~mol}^{1}$ & 177 & 68 & 77 & 66 & 71 & 72 \\
\hline
\end{tabular}

are not steady-state. It seems, however, over a wide range of temperature and stress, that the steady-state tertiary creep is related to the minimum crecp rate (for a given stress configuration) by a constant enhancement factor (e.g. Budd and Jacka, 1989). Thus, the activation energies in steady-state tertiary creep will be similar to those at minimum.

$\mathrm{Li}(1994)$ has carried out a set of laboratory tests to examine ice-crystal growth (under no stress) over the temperature range $-0.1^{\circ}$ to $-5.0^{\circ} \mathrm{C}$. Li's test samples were both laboratory-prepared (Jacki and Lilc, 1984) and cut from an Antarctic ice core. Samples were placed in a plastic bag which was then immersed in a silicon oil bath with accurate temperature control. After different time intervals (ranging from days to months), samples were removed, thin sections cut, then replaced for a further time. Thin sections were measured for crystal-size and growth rates calculated for the range of temperatures. Li's calculation of activation energies for crystal growth are shown in Table 2. Also shown in Table 2 are calculations of crystal-growth activation energies for temperatures down to $-60^{\circ} \mathrm{C}$. These calculations are based on smooth curves through the ficld data (shown in Figure l) of $\mathrm{Li}$ (1994) and Gow (1969).

$\mathrm{Li}$ (1994) also examined some field data from Law Dome, Antarctica, and from Gow's (1969, 1970) work. The agreement between the laboratory and the field data is excellent and both are shown in Figure 1, a plot of crystal-growth rate as a function of $1 / T$ where $T$ is ice temperature (K). To compare the shape of the curves, minimum strain rate (after Morgan, 1991) is plotted on the same scale. The similarity of these two data sets, neither of which has been subjected to any smoothing, is remarkable.

Figure 2 is a plot of the two activation energies, also as a function of $1 / T$. It is seen that the activation energies for the two processes, icc-crystal growth and ice creep appear, over this temperature range, to be particularly similar. It remains now to test the hypothesis that equilibrium steady-state crystal size is a function of stress alone.

Table 2. Calculation of activation energy for ice-crystal growth

\begin{tabular}{|c|c|c|c|c|c|c|c|}
\hline$\theta_{1},{ }^{\circ} \mathrm{C}$ & -0.10 & -1.00 & -3.00 & -6.00 & -10.00 & -20.00 & -40.00 \\
\hline$\theta_{2},{ }^{\circ} \mathrm{C}$ & -1.00 & -3.00 & -6.00 & -10.00 & -20.00 & -40.00 & -60.00 \\
\hline $1 / T_{1}, \mathrm{~K}^{\prime}$ & $3.66 \times 10^{-3}$ & $3.68 \times 10^{-3}$ & $3.70 \times 10^{3}$ & $3.75 \times 10^{3}$ & $3.80 \times 10^{3}$ & $3.95 \times 10^{3}$ & $4.29 \times 10^{3}$ \\
\hline $1 / T_{2}, \mathrm{~K}^{1}$ & $3.68 \times 10^{-3}$ & $3.70 \times 10^{-3}$ & $3.75 \times 10^{-3}$ & $3.80 \times 10^{-3}$ & $3.95 \times 10^{3}$ & $4.29 \times 10^{3}$ & $4.69 \times 10^{3}$ \\
\hline$\left(1 / T_{2}-1 / T_{1}\right), \mathrm{K}^{-1}$ & $1.21 \times 10^{5}$ & $2.72 \times 10^{-5}$ & $4.16 \times 10^{5}$ & $5.70 \times 10^{5}$ & $1.50 \times 10^{4}$ & $3.39 \times 10^{4}$ & $4.03 \times 10^{4}$ \\
\hline$\dot{\epsilon}_{1}, \mathrm{~mm}^{2} \mathrm{a}$ & $3.15 \times 10^{1}$ & 2.01 & $4.07 \times 10^{-1}$ & $1.11 \times 10^{1}$ & $6.52 \times 10^{2}$ & $2.02 \times 10^{2}$ & $3.35 \times 10^{3}$ \\
\hline$\dot{\epsilon}_{2}, \mathrm{~mm}^{2} \mathrm{a}$ & 2.01 & $4.07 \times 10^{-1}$ & $1.11 \times 10^{-1}$ & $6.52 \times 10^{-2}$ & $2.02 \times 10^{2}$ & $3.53 \times 10^{3}$ & $3.90 \times 10^{4}$ \\
\hline $\ln \left(\dot{\epsilon}_{2} / \dot{\epsilon}_{1}\right)$ & -2.752 & -1.597 & -1.299 & -0.532 & -1.172 & -1.744 & -2.150 \\
\hline $\ln \left(\dot{\epsilon}_{2} / \dot{\epsilon}_{1}\right) /\left(1 / T_{2}-1 / T_{1}\right)$ & $-2.27 \times 10^{5}$ & $-5.86 \times 10^{4}$ & $-3.12 \times 10^{4}$ & $-9.34 \times 10^{3}$ & $-7.80 \times 10^{3}$ & $-5.14 \times 10^{3}$ & $-5.34 \times 10^{3}$ \\
\hline$Q, \mathrm{~kJ} \mathrm{~mol}{ }^{1}$ & 1886 & 487 & 259 & 78 & 65 & 43 & 44 \\
\hline
\end{tabular}




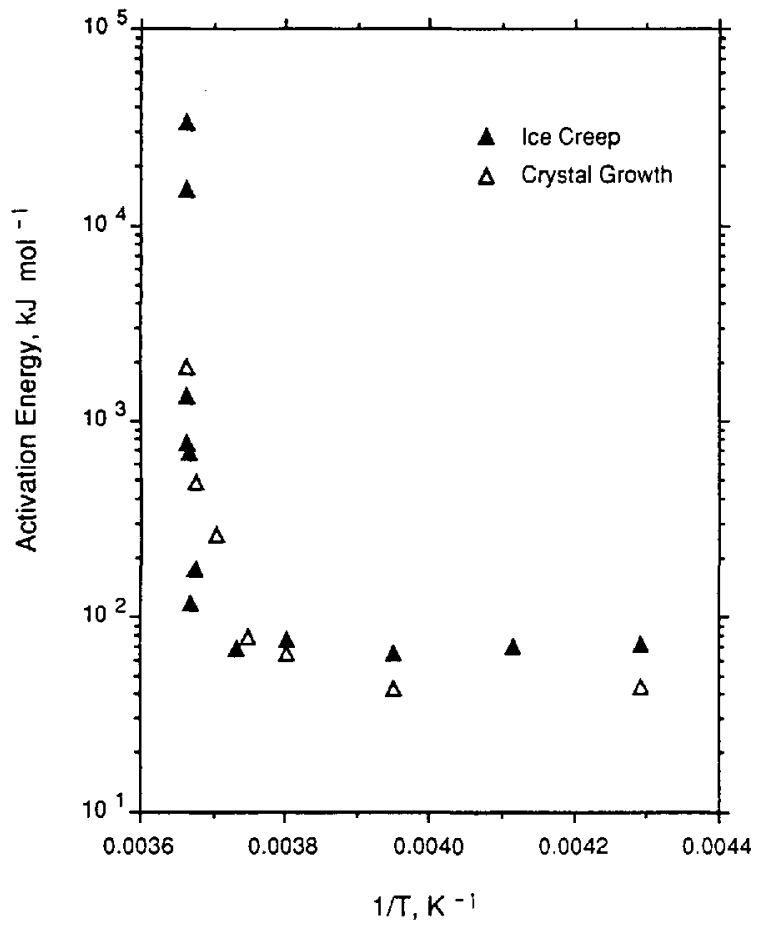

Fig. 1. Ice-crystal growth rates (after Gow (1969) and Li (1994)) and creep rales (after Morgan (1991)) as a function of the inverse of the temperature $(K)$ for a range of laboratory and field experiments.

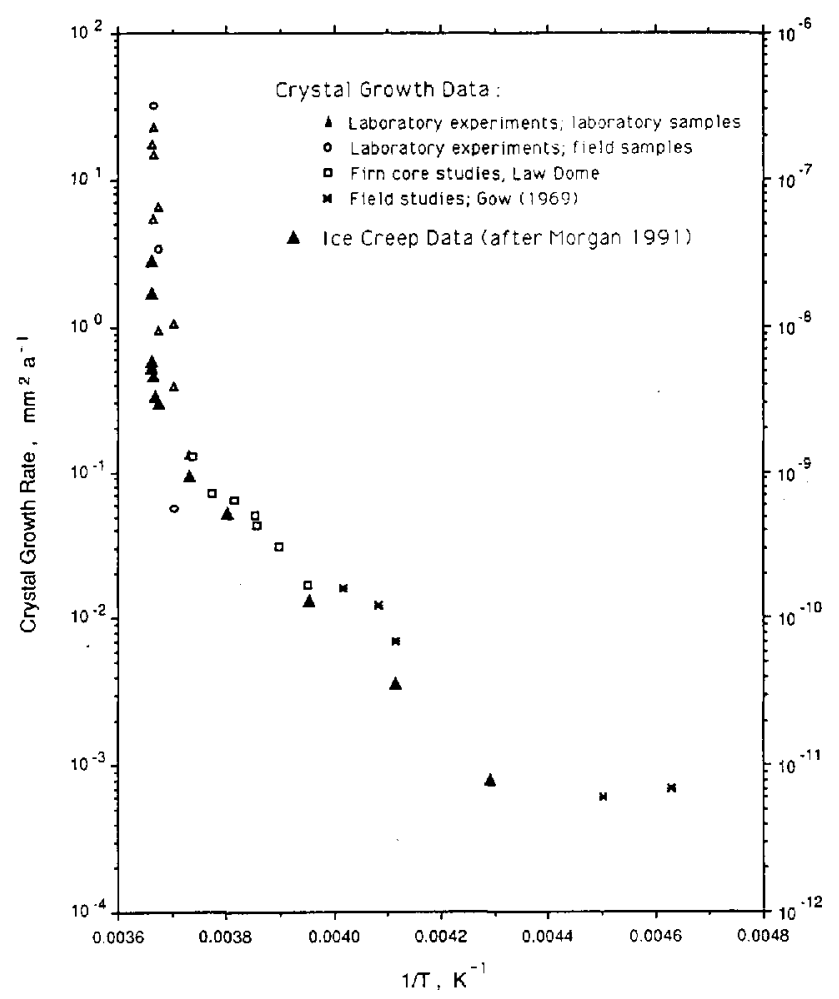

Fig. 2. Activation energy for the two processes, ice-crystal groweth and ice creep, as a function of the inverse of the temperature $(K)$.

\section{STEADY-STATE CRYSTAL SIZE AS A FUNCTION OF STRESS}

Table 3 shows steady-state crystal sizes achieved from several ice-deformation tests carried out in uniaxial compression over a range of stresses and temperatures.
Table 3. Equilibrium steady-state crystal size for a range of temperatures, octahedral shear stresses, steady-state tertiary strain rates and initial crystal sizes

\begin{tabular}{|c|c|c|c|c|c|}
\hline Temp. & $\begin{array}{l}\text { Oct. } \\
\text { shear } \\
\text { stress }\end{array}$ & $\begin{array}{c}\text { Steady-state } \\
\text { strain rate } \\
\text { size }\end{array}$ & $\begin{array}{l}\text { Initial } \\
\text { crystal } \\
\text { size }\end{array}$ & $\begin{array}{c}\text { Sleady- } \\
\text { state crystal }\end{array}$ & Ref. \\
\hline${ }^{\circ} \mathrm{C}$ & $\mathrm{MPa}$ & $s^{1}$ & $\mathrm{~mm}^{2}$ & $\mathrm{~mm}^{2}$ & \\
\hline-10.0 & 0.20 & $7.00 \times 10^{9}$ & 1.2 & 1.7 & 1 \\
\hline 10.0 & 0.30 & $4.80 \times 10^{8}$ & 1.2 & 2.1 & 1 \\
\hline 10.0 & 0.40 & $9.80 \times 10^{8}$ & 1.2 & 1.1 & 1 \\
\hline-10.0 & 0.50 & $2.00 \times 10^{7}$ & 1.2 & 1.0 & 1 \\
\hline-10.0 & 0.60 & $3.80 \times 10^{7}$ & 1.2 & 0.9 & 1 \\
\hline-10.0 & 0.30 & $2.90 \times 10^{8}$ & 5.8 & 1.6 & 1 \\
\hline 10.0 & 0.40 & $7.20 \times 10^{-8}$ & 5.8 & 0.9 & 1 \\
\hline 10.0 & 0.60 & $3.50 \times 10^{-8}$ & 5.8 & 0.7 & 1 \\
\hline-10.0 & 0.80 & $1.10 \times 10^{-8}$ & 5.8 & 0.5 & 1 \\
\hline-10.0 & 1.00 & $3.60 \times 10^{-8}$ & 5.8 & 0.3 & 1 \\
\hline-5.0 & 0.20 & $6.00 \times 10^{-8}$ & 1.2 & 2.7 & 1 \\
\hline-5.0 & 0.40 & $3.30 \times 10^{-7}$ & 1.2 & 1.1 & 1 \\
\hline-5.0 & 0.60 & $1.40 \times 10^{-6}$ & 1.2 & 0.7 & 1 \\
\hline 5.0 & 0.80 & $5.60 \times 10^{-6}$ & 1.2 & 0.6 & 1 \\
\hline 5.0 & 1.00 & $1.30 \times 10^{-5}$ & 1.2 & 0.2 & 1 \\
\hline-5.0 & 0.25 & $6.67 \times 10^{8}$ & 2.0 & 1.7 & l \\
\hline-5.0 & 0.25 & $6.42 \times 10^{8}$ & 2.0 & 2.3 & I \\
\hline-5.0 & 0.25 & $6.79 \times 10^{8}$ & 2.0 & 2.0 & 1 \\
\hline-3.0 & 0.20 & $1.10 \times 10^{7}$ & 1.2 & 2.0 & I \\
\hline-3.0 & 0.30 & $2.20 \times 10^{7}$ & 1.2 & 1.8 & 1 \\
\hline-3.0 & 0.40 & $6.40 \times 10^{7}$ & 1.2 & 1.5 & 1 \\
\hline-3.0 & 0.50 & $1.10 \times 10^{6}$ & 1.2 & 0.6 & 1 \\
\hline-3.0 & 0.60 & $2.60 \times 10^{6}$ & 1.2 & 0.6 & 1 \\
\hline-3.0 & 0.80 & $8.80 \times 10^{6}$ & 1.2 & 0.2 & 1 \\
\hline-2.0 & 0.20 & $8.53 \times 10^{-8}$ & 1.0 & 4.0 & l \\
\hline-2.0 & 0.60 & $1.26 \times 10^{6}$ & 1.0 & 0.1 & l \\
\hline-0.1 & 0.10 & $5.00 \times 10^{-8}$ & 1.2 & 13.6 & 1 \\
\hline-0.1 & 0.20 & $2.10 \times 10^{-7}$ & 1.2 & 6.3 & 1 \\
\hline-0.1 & 0.20 & $1.30 \times 10^{-7}$ & 1.2 & 7.3 & 1 \\
\hline-3.0 & 0.20 & $6.00 \times 10^{-8}$ & 4.0 & 21.2 & 2 \\
\hline-3.3 & 0.30 & $1.32 \times 10^{7}$ & 4.8 & 1.4 & 3 \\
\hline-3.3 & 0.30 & $1.12 \times 10^{-7}$ & 6.8 & 1.0 & 3 \\
\hline-3.3 & 0.30 & $9.50 \times 10^{-8}$ & 6.8 & 0.8 & 3 \\
\hline-3.3 & 0.20 & $3.25 \times 10^{-8}$ & 2.3 & 1.4 & 3 \\
\hline 3.3 & 0.30 & $2.43 \times 10^{7}$ & 0.5 & 2.0 & 4 \\
\hline-3.3 & 0.30 & $2.54 \times 10^{-7}$ & 0.5 & 1.4 & 4 \\
\hline-3.3 & 0.20 & $3.63 \times 10^{-7}$ & 0.5 & 3.6 & 4 \\
\hline
\end{tabular}

References:

1. This study.

2. Jacka and Maccagnan (1984).

3. Gao and Jacka (1987); Law Dome ice-core samples.

4. Gao and Jacka (1987); laboratory-prepared samples.

For each of these (constant-stress) tests, the total strain exceeded $15 \%$ and a constant tertiary creep rate (also shown in Table 3) was achieved. A preferred crystalorientation fabric (for compression, a small-circle girdle pattern) was established for each test. 


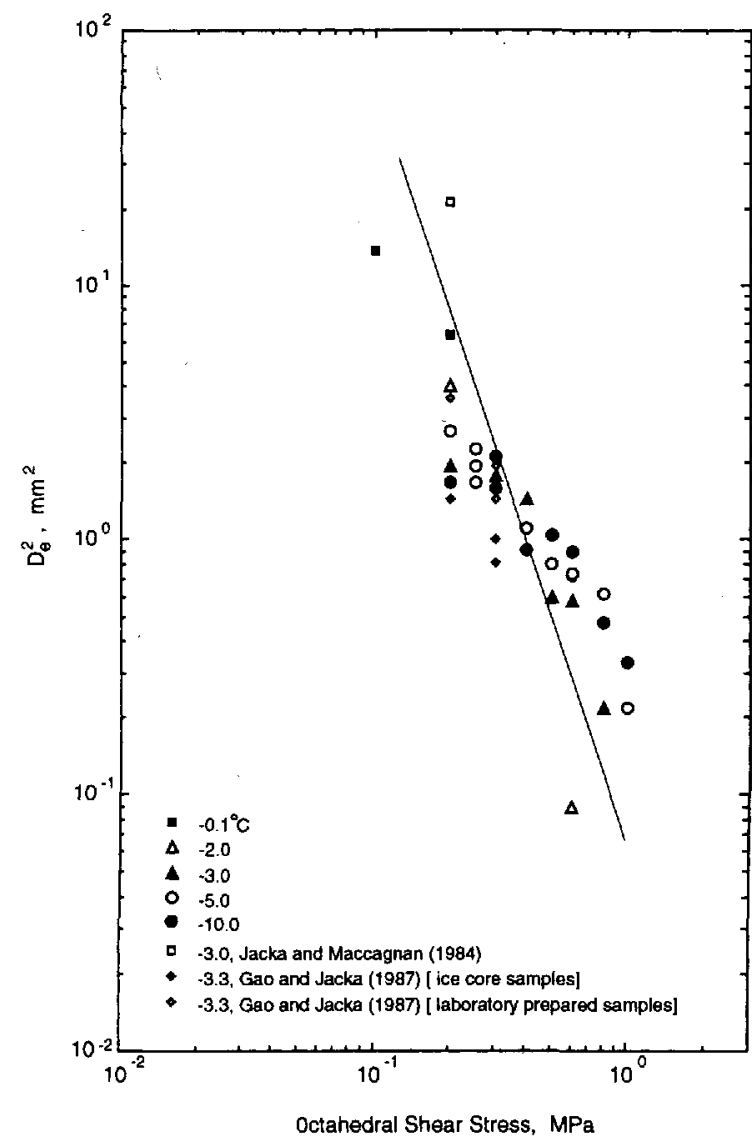

Fig. 3. The square of the equilibrium steady-state crystal diameter, $D_{\mathrm{e}}$, as a function of the octahedral shear stress for a range of ice-creep tests at several different temperatures. The straight line has been drawn with a slope of -3 .

Figure 3 is a plot on log scales of the square of the equilibrium crystal diameter (from the data of Table 3 ) as a function of the octahedral shear stress applied for each test. The straight line of Figure 3 has been drawn with a slope of -3 . From the plot, there does not appear to be any trend with temperature (over the range $-0.1^{\circ}$ to $-10.0^{\circ} \mathrm{C}$ ) which is indicated by different symbols. Although the variability in the measure of crystal size is large, the plot provides strong support for the dependence of steady-state crystal size on stress alone. Furthermore, the data provide some support for the hypothesized relationship:

$$
D_{\mathrm{f}}^{2} \propto 1 / \tau^{3}
$$

However, it is clear from the plot that more data are required to test fully the above relationship. In particular, data are required for crystal sizes greater than $\sim 10 \mathrm{~mm}^{2}$ (requiring lower stresses and therefore extremely long times to attain steady-state ice flow) and for crystal sizes less than $\sim 0.2 \mathrm{~mm}^{2}$ (i.e. so small that size measurement is particularly difficult). It is expected that the imminent introduction of automatic computer-controlled and microscope-based ice-crystal thin-section analysers will alleviate the problems encountered in the routine and consistent measurement of crystal size.

With the exception of some early work by Steinemann (1958), to these authors' knowledge, a dependence of crystal size on deviatoric stress has not previously been established for ice. However, this phenomenon is not new with respect to other crystalline materials. 'The relationship

$$
D \propto 1 / \tau^{r}
$$

where $D$ is linear crystal dimension, $\tau$ is applied stress and $r$ is a constant, has been found for a range of materials, e.g. quartzite, olivine, dunite, pyrite, halite and nickel (Poirier, 1985), where $\sim 1.0 \leq r \leq \sim 1.5$. These values of $r$ compare with $r=n / 2=1.5$ found here for ice.

\section{ON THE POTENTIAL USE OF STEADY-STATE GRYSTAL SIZE AS A PIEZOMETER}

The existence of a relationship between crystal size and stress raises the possibility that crystal size might be useful as an indicator of the deviatoric stress within polar ice masses. While in-situ stress is not able to be directly measured, crystal size is measured routinely in the deep ice cores (e.g. Gow and Williamson, 1976; Herron, 1982; Li and Jacka, 1994).

Of course, it needs to be recognized that ice in the natural ice masses is not always steady-state and therefore that a relation such as that found here will not be applicable throughout the depth. In the firn layers, where the stress is near zero, the crystal-growth rate has been described by Gow $(1969,1970)$. This relation also holds in the deep bedrock layers of near-stagnant (i.e. low-stress or, sometimes, stress-relaxation) ice at warmer temperatures where, on occasions, extremely large crystals have been found in ice cores down to bedrock. At intermediate depths, the ice is subject to changing stress, changing stress-configuration and changing temperature as it progresses deeper into the ice sheet. This is evidenced, for example, by variations in crystal-orientation fabric through the deep ice cores. However, the rate of change of these parameters is particularly slow, occurring over hundreds of years, and it must be said therefore that the ice throughout most of the depth of the polar ice sheets is in near-steady-state creep. For most of the depth, therefore, a relationship such as that found here between steady-state crystal size and deviatoric stress may prove valuable. Further work continues on this topic and will be published elsewhere.

\section{CONCLUSIONS}

On the basis of observations from field and laboratory studies, it is known that ice-crystal size is a result of deformation to high strains. Crystal size seems to be independent of the structural (crystal size and orientation) or deformational (stress, stress-configuration and strain-rate) history. Rather, it is a product of the in-situ contemporaneous conditions.

Under no stress, the mean ice-crystal size increases at a rate dependent on temperature. If a stress is applied, the crystal growth is modified and at large strains, as the ice attains steady-state creep, an equilibrium crystal size is reached. This equilibrium steady-state mean crystal size is 
considered as a "balance" between the growth as a function of temperature and the deformation due to strain. This approach reveals a dependence of equilibrium crystal sizc on the ratio of the temperature effects, i.c. of the activation energies for the two processes - icecrystal growth and ice creep. The temperature-dependence for ice crecp has been examined by several authors and is now well understood. Similarly, the temperaturedependence for ice-crystal growth is well understood. Recent observations of both these processes at temperatures nearer to the melting point $\left(-2.0^{\circ}\right.$ to $\left.>-0.1^{\circ} \mathrm{C}\right)$, where crystal-growth/deformation rates are higher, have now made it possible to compare these processes in more detail. It appears from the data that the activation encrgies (i.e. the temperature-dependence) for the two processes are similar. Therefore, that the dependence of steady-state crystal size on temperature is small, and that crystal size is a function of deviatoric stress alone. Furthermore,

$$
D_{\mathrm{e}}^{2} \times 1 / \tau^{n}
$$

where $n$ is the power-law constant. The value of $n$ has also been the subject of much study and is generally accepted to have a value of 3 . The experimental data of stcady-state crystal size as a function of stress provides support for this relation. A dependence similar to that above, of crystal size on stress, is known for other crystalline minerals and values of $r$ for these minerals have gencrally becn found empirically to be in the same range as found here for ice.

The use of crystal size in natural ice masses as a piezometer may prove particularly valuable as a glaciological tool for investigations of the dynamics of the polar ice sheets. This is the subject of investigations currently in progress.

\section{REFERENCES}

Budd, W.F. 1972. The development of crystal orientation fabrics in moving icc. Z. Giletscherkd. Gtazialgeol., 8(1-2), 65105.

Budd, W. F. and 'T. H. Jacka. 1989. A review of ice rheology for ice sheet modelling. Cold Reg. Sci. Technol., 16 2), 107-144.

Duval, $\mathrm{P}$. and C. Lorius. 1980. Crystal size and climatic record down to the last ice age from Antarctic ice. Eanth Planel. Sci. Lett., 48, 59-64.

Fisher, D.A. and R. M. Koerner. 1986. On the special rheological properties of ancient microparcicle-laden Northern Hemisphere ice as derived from bore-hole and core masurements. 7. Glaciol., 32(112), 501510 .

Gao, X. Q. and T.II. Jacka. 1987. The approach to similar tertiary crecp rates for Antarctic core ice and laboratory prepared ice. If Phys. (Paris), 48, Colloq. C1, 289-296. (Supplément au 3.)

Glen, J. W. 1955. The creep of polycrystalline ice. Proc. R. Soc. Londom, Ser. A, $228(1175), 519-538$.
Gow, A.J. 1969. On the rates of growth of grains and crystals in south polar firn. J. Glaciol., 8(53), 241252.

Gow, A.J. 1970. Deep corr studies of the crystal structure and fabrics of Antarctic glacicr icc. CRREL. Res. Rep. 282.

Gow, A.J. and T. Williamson. 1976. Rheological implications of the internal structure and crystal fabrics of the West Antarctic ice shect as reveated by deep core drilling at Byrd Station. CRREL Rep. 76-35.

Herron, S. L. 1982. Physical properties of the deep ice core from Camp Century, Greenland. (Ph.D. thesis, State University of New York at Bullalo.)

Jacka, T.H. 1984. Laboratory studies on relationships between ice crystal size and flow rate. Cold Reg. Sci. Technol., 10 1), 3142.

Jacka, T.H. and R. C. Lilc. 1984. Sample preparation techniques and compression apparatus for ice flow studics. Cold Reg. Sci. Technol, 8(3), 235-240.

Jacka, T.H. and M. Maccagnan. 1984. Ice crystallographic and strain ratc changes with strain in compression and extension. Cold Reg. Sci. Technol, 8 (3), 269-286.

Kamb, W. B. 1964. Glacier geophysics. Science, 146 3642), 353365.

Korotkevich, Yc.S., V.N. Petrov, N. I. Barkov, L. I. Suchonosova, D. N. Dmitriev and V. G. Portnov. 1978. The results of Antarctic ice sheet vertical structure studies near Vostok Station. Information Bulletin of the Soutet Antarctic Expedition, 97, 135-148.

Li Jun. 1994. Interrelation between flow properties and crystal structure of snow and ice. (Ph.1). thesis, University of Melbourne.)

Li Jun and T. H. Jacka. 1994. The crystallography of the 1,200m DSS ice core, Law Dome, East Antarctica. Antartic CRC Research Report.

Morgan, V.I. 1991. High-temperalure ice creep tests. Cold Reg. Sci. Technot., 19(3), 295-300.

Paterson, W.S. B. 1981. The physics of glaciers. Second edition. Oxford, etc., Pergamon Press.

Paterson, W. S. B. 1991. Why ice-age ice is sometimes soft. Cold Reg. Sci. Technol., 20(1), 75-98.

Pctit, J. R., P. Duval and C. Lorius. 1987. I.ong-term climatic changes indicated by crystal growth in polar ice. Nature, 326/6108), 62-64.

Poirier, J. -P. 1985. Creep of crystals. Cambridge, Cambridge University Press.

Russell-Head, D.S. and W.F. Budd. 1979. Ice-sheet flow properties derived from bore-hole shear measurements combined with ice-core studies. J. Glaciol, $2490 ;, 117130$.

Seligman, G. 1949. The growth of the glacier crystal. J. Glaciol., 1(5), $254-267$.

Seligman, G. 1950. The growth of the glacier crystal. Some further notes. 7. Glaciol., $1(7), 379-381$.

Stcinemann, S. 1958. Resultats experimentaux sur la dynamique de la glace et leurs correlations avec le mowvement et la petrographie de glaciers. International Association of IIydrological Sciences Publication 47 IUGG/LASH Symposium of Chamonix, 184-198.

Stcphenson, P.J. 1967. Some considerations of snow metamorphism in the Antarctic ice sheet in the light of the ice crystal studies. In Oura, H., ed. Physics of snow and ice. Institute of Low Temperature Science, Hokkaido University, 1, 725-740).

Weertman, J. 1973. Creep of ice. In Whalley, E., S.J. Jones and L. W. Gold, eds. Physics and chemistry of ice. Ottawa, Royal Society of Canada, 320-337.

Weertman, J. 1983. Creep deformation of ice. Ann. Rev. Earth Planet. Sci., $11,215 \cdot 240$

Young, N.W., Xie Zichu and Qin Dahe. 1985. Multilaycr crystallographic structure of Law Dome from ice core analysis. In Jacka, T. H., ed. Australian glaciological research, 1982 1983. ANARE Research Votes $28,18-24$.

The accuracy of references in the text and in this list is the responsibility of the authors, to whom queries should be addressed. 